\title{
Glutathione, Vitamin C, Malonodialdehyde Oxidized Low-Density Lipoprotein and Lipid Profile Levels in Type 2 Diabetic Iraqi Males
}

\author{
Shakir Faris Tuleab \\ Department of Chemistry, College of Education for Pure Sciences, University of Anbar.
}

\begin{abstract}
Diabetes is a devastating disease throughout the world. It is associated with several mechanisms, one of which is oxidative stress. Oxidative stress plays an important role in the pathogenesis and the complications of diabetes. Hyperglycemia results in overproduction of oxygen free radicals, which contributes to the progression of diabetes. This study was designed to evaluate the status of serum Glutathione, Vitamin C, Malonodialdehyde and Oxidized Low-Density Lipoprotein levels in male patients with type 2 diabetes mellitus. A total study subject of 82 were examined, including 46 patients with type $2 \mathrm{DM}$ and 36 healthy individuals as a control group matched for age, sex, and body mass index (BMI). Blood samples were drawn after an overnight fasting for the determination of serum glucose, HbA1c, urea, uric acid, insulin, GSH, MAD, OX-LDL, Vit C, and lipid profile. It was found that total diabetic patients had higher FSG, HbA1c, urea, FSI, OX-LDL, MDA, TC, TG, LDL, and VLDL levels and lower UA, GSH and Vit C levels when comparing with control groups. The prevalence oxidative stress among type $2 \mathrm{DM}$ patients is very high with deslipidemia is being most common continuous monitoring of glucose and lipid profile in diabetic patients is essential to reduce the mortality rate.
\end{abstract}

Keywords: Diabetes mellitus, Glutathione, Malonodialdehyde, Vitamin C.

\section{Introduction}

Type 2 diabetes mellitus (DM) is explained by genetic, and environmental factors, and insulin resistance. ${ }^{[1]}$ HbA1c level provides an index of the average blood glucose concentration over the previous 2-3 months. ${ }^{[2]}$ Presently, HbA1c is the most acceptable and widely used measure of chronic glycemia. ${ }^{[3]}$

Type 2 diabetes is associated with reduced life expectancy, significant morbidity due to the specific diabetes related microvascular complications (retinopathy, nephropathy and neuropathy), and the increased risk of macrovascular complications (ischemic heart disease, stroke and peripheral vascular disease). ${ }^{[4]}$

Diabetes produces disturbances of lipid profiles, especially an increased susceptibility to lipid peroxidation, which is responsible for increased incidence of atherosclerosis, a major complication of diabetes mellitus. ${ }^{[5]}$

The development of these complications impacts on quality of life. Normally, levels of reactive oxygen species (ROS) are regulated by variety of enzymatic and non-enzymatic antioxidant systems. But increased production and/or inadequate removal of ROS may cause oxidative stress, imbalance between prooxidant and antioxidants which can lead to oxidative damage to biological macromolecules. ${ }^{[6]}$

Under normal conditions free radicals are formed in minute quantities and are rapidly scavenged by natural cellular defense mechanism. Lipidperoxidation products Malonodialdehyde (MDA), which increases in clinical and experimental diabetes, are important results of oxygen derived free radicals stress. These products may be important in the pathogenesis of vascular complications in diabetes mellitus. ${ }^{[7]}$

Glutathione (GSH) is the major cellular antioxidant that protects against environmental toxicants as well as reactive oxygen species (ROS) mediated cell injury. GSH detoxifies ROS, reduces peroxides and detoxifies multiple compounds through glutathione-Stransferase (GST) conjunction. ${ }^{[8]}$ Vitamin $\mathrm{C}$ is an important antioxidant in human', capable of scavenging oxygen-derived free radicals'. Several studies showed decreased basal vitamin $\mathrm{C}$ level in diabetic patients and also it is suggested that oxidative stress is increased in diabetes. ${ }^{[9]}$

Several studies have shown that diabetes mellitus (types I and II) is accompanied by 
increased formation of free radicals and decreased antioxidant capacity, leading to oxidative damage of cell components. [10-12] Patients with T2DM exhibit low HDL-C levels. ${ }^{[13]}$

LDL oxidation initiates a series of events that ultimately will lead to increased acquisition of LDL by macrophages, the formation of foamy cells and the development board aterom. ${ }^{[14]}$

\section{Patients and Methods}

The present study was carried out in the National Diabetes Center for Treatment and Research at Al-Mustansiriya University between July 2012- March 2013. A total of 46 patients of type 2 diabetes mellitus (males of age group38-68 years.), who were already diagnosed to have type 2 diabetes mellitus based on the criteria of the expert committee on the diagnosis and classification of diabetes mellitus. 36 age and sex matched (males) healthy individuals served as controls who attended for routine health check up at the center. None of the healthy control was taking any medicine or dietary supplement; they were selected after detailed physical examination and laboratory tests. Samples collection: After $12 \mathrm{hrs}$ fasting $6 \mathrm{ml}$. venous blood sample was collected in plain tubes, the samples were allowed to clot for half an hour following which a samples were centrifuged for 15 minutes at $4000 \mathrm{rpm}$. Serum was stored immediately at $-20 \mathrm{C}$ until analysis. Serum glucose was determined by a glucose oxidase method (Randox Company, U.K.). ${ }^{[15]}$ creatinine, uric acid and urea were measured by colorimetric method (LINER Chemicals/ Spain).Vitamin $\mathrm{C}$ was determined by highperformance liquid chromatography (HPLCUV). ${ }^{[16]}$ Total cholesterol, triglycerides and HDL cholesterol were measured by enzymatic analytical chemistry (CHOD-PAP method, Roche Diagnostics, Milan, Italy). ${ }^{[17]}$ Serum Malondialdehyde (MDA) was measured by enzyme linked immunosorbentassay ELISA (KA1206, Taipei City, Taiwan). Glutathione (GSH) level was performed using a quantitative sandwich ELISA immunoassay (CSB-E09495h, Wuhan, Hubei, China). serum Insulin level was performed using a quantitative sandwich ELISA immunoassay
(DRG diagnostics Company, Germany). oxLDL level in human serum was performed using a quantitative sandwich ELISA immunoassay (Human Company, Germany). Glycated hemoglobin was measured by using the Variant Hemoglobin A1C program developed by BIO-Rad.

\section{Statistical Analysis}

All data have been presented as mean \pm SD. One-way analysis of variance (ANOVA) was performed on each variable and the Bonferroni statistics employed to compare the mean values from the different groups. Un paired t-test was used to assess the effect between groups. Differences were considered significant at $\mathrm{P}<0.05$. All statistical analyses were performed using SPSS statistical software (version 19).

\section{Results and Discussion}

Clinical and biochemical characteristics of the study population, i.e. control and type 2 diabetic men are given in Table (1), Figs.(1,2). Waist shows significant differences between the two groups in waist circumference $(p<0.05)$ but no significant differences between the two groups in hip circumference.

The mean value of fasting serum glucose $187.90 \pm 48.16 \mathrm{mg} / \mathrm{dl}$, HbA1c $8.13 \pm 1.74 \%$., serum urea $37.06 \pm 5.90 \mathrm{mg} / \mathrm{dl}$, serum creatinine $1.25 \pm 0.20 \mathrm{mg} / \mathrm{dl}$ in diabetic males and $\quad 93.13 \pm 6.93 \mathrm{mg} / \mathrm{dl}, \quad 4.85 \pm 0.31 \%$, $31.32 \pm 4.65 \mathrm{mg} / \mathrm{dl}, 1.02 \pm 0.16 \mathrm{mg} / \mathrm{dl}$ in control group, respectively.

There was a highly significant increase in fasting serum insulin $5.69 \pm 2.50 \mu \mathrm{IU} / \mathrm{ml}$ in control and $17.73 \pm 6.27 \mu \mathrm{IU} / \mathrm{ml}$ in the patients of type 2 diabetes, $(\mathrm{p}<0.0001)$. 
Table (1)

Baseline characteristics of the study Parameters.

\begin{tabular}{|c|c|c|c|c|c|}
\hline \multicolumn{2}{|l|}{ Parameters } & Mean $\pm S . D$ & Cohen's d & $t$ & $P$-value \\
\hline \multirow{2}{*}{ Waist cm } & cases & $113.00 \pm 10.19$ & \multirow{2}{*}{0.581} & \multirow{2}{*}{-2.540} & \multirow{2}{*}{0.013} \\
\hline & controls & $107.16 \pm 9.92$ & & & \\
\hline \multirow{2}{*}{ Hip $\mathrm{cm}$} & cases & $112.96 \pm 9.83$ & \multirow{2}{*}{0.145} & \multirow{2}{*}{-0.650} & \multirow{2}{*}{0.518} \\
\hline & controls & $111.42 \pm 11.33$ & & & \\
\hline \multirow{2}{*}{ F.S.G mg/dl } & cases & $187.90 \pm 48.16$ & \multirow{2}{*}{2.755} & \multirow{2}{*}{-10.863} & \multirow{2}{*}{0.000} \\
\hline & controls & $93.13 \pm 6.93$ & & & \\
\hline \multirow{2}{*}{ HbA1c\% } & cases & $8.13 \pm 1.74$ & \multirow{2}{*}{2.616} & \multirow{2}{*}{-10.340} & \multirow{2}{*}{0.000} \\
\hline & controls & $4.85 \pm 0.31$ & & & \\
\hline \multirow{2}{*}{ F.S.I $\mu I U / m l$} & cases & $17.73 \pm 6.27$ & \multirow{2}{*}{2.524} & \multirow{2}{*}{-10.197} & \multirow{2}{*}{0.000} \\
\hline & controls & $5.69 \pm 2.50$ & & & \\
\hline \multirow{2}{*}{ S. Urea mg/dl } & cases & $37.06 \pm 5.90$ & \multirow{2}{*}{1.080} & \multirow{2}{*}{-4.609} & \multirow{2}{*}{0.000} \\
\hline & controls & $31.32 \pm 4.65$ & & & \\
\hline \multirow{2}{*}{ S. Creatinine mg/dl } & cases & $1.25 \pm 0.20$ & \multirow{2}{*}{1.248} & \multirow{2}{*}{-5.354} & \multirow{2}{*}{0.000} \\
\hline & controls & $1.02 \pm 0.16$ & & & \\
\hline & cases & $197.57 \pm 51.16$ & & & \\
\hline Total. C mg/dl & controls & $10151.71 \pm 16.42$ & 1.207 & -4.8 & 0.000 \\
\hline$T C \mathrm{moldl}$ & cases & $167.14 \pm 74.72$ & 1216 & 4820 & $0 \Omega 00$ \\
\hline I.G mg/dl & controls & $101.39 \pm 16.16$ & 1.210 & -4.820 & 0.000 \\
\hline & cases & $43.76 \pm 6.70$ & 1420 & 6013 & $0 \Omega 00$ \\
\hline HDL & controls & $52.10 \pm 4.90$ & 1.420 & 0.013 & 0.000 \\
\hline & cases & $119.61 \pm 47.53$ & & & \\
\hline LDL mg/dl & controls & $78.74 \pm 16.25$ & 1.151 & -4.616 & 0.000 \\
\hline VI DI mo/dl & cases & $33.37 \pm 14.73$ & 1222 & 4844 & $0 \Omega 00$ \\
\hline VLDL mg/dl & controls & $20.35 \pm 3.15$ & 1.222 & -4.844 & 0.000 \\
\hline MDA nmol/ml & cases & $6.38 \pm 1.25$ & 2753 & 11476 & $0 \Omega 00$ \\
\hline IIDA nmol/mi & controls & $3.52 \pm 0.78$ & 2.153 & $4 / 6$ & 0.000 \\
\hline & cases & $24.70 \pm 11.12$ & & & \\
\hline OX-LDL U/ml & controls & $10.40 \pm 2.69$ & 0.171 & -0.252 & 0.000 \\
\hline $\mathrm{CCH}$ & cases & $1.49 \pm 0.37$ & 1575 & 7478 & 0000 \\
\hline GSH $\mu \mathrm{g} / \mathrm{ml}$ & controls & $2.38 \pm 0.71$ & $1.5 / 5$ & $1.4 / 8$ & 0.000 \\
\hline Vitomin $\mathrm{Cma} / \mathrm{dl}$ & cases & $1.03 \pm 0.24$ & & & $0 \Omega 0$ \\
\hline Vitamın C mg/dl & controls & $1.44 \pm 0.41$ & 1.223 & 5.131 & 0.000 \\
\hline & cases & $4.51 \pm 0.70$ & & & \\
\hline S.U.A mg/dl & controls & $5.37 \pm 0.61$ & 1.295 & 5.589 & 0.000 \\
\hline
\end{tabular}

There was a highly significant increase in FSG, HbA1c, S. urea and $\mathrm{S}$. creatinine in patient group compared to the control group $(\mathrm{p}<0,0001)$.

Biochemical lipid profile characteristics (TC, TG, HDL-C, LDL-C and VLDL) are shown in Table (1), Fig.(1). There was a highly significant increase in serum TC, TG, LDL-C, VLDL-C and a highly significant decrease in HDL-C in the patient group compared to the control group $(\mathrm{p}<0,0001)$.

There was a highly significant increase in serum MDA and ox-LDL in patient group compared to the control group $(\mathrm{p}<0,0001)$.
The mean value of MDA $6.38 \pm$ $1.25 \mathrm{nmol} / \mathrm{ml}$, ox-LDL $24.70 \pm 11.12 \mathrm{U} / \mathrm{ml}$ in diabetic males and $3.52 \pm 0.78 \mathrm{nmol} / \mathrm{ml}$, $10.40 \pm 2.69 \mathrm{U} / \mathrm{ml}$. in control group, respectively.

Serum vitamin C, GSH and uric acid levels are significantly lower in the diabetic men there was significant increase in blood urea and serum creatinine in diabetic control subjects. Similar results were observed in Diabetic Nepalese. [20] Due to high blood sugar. 


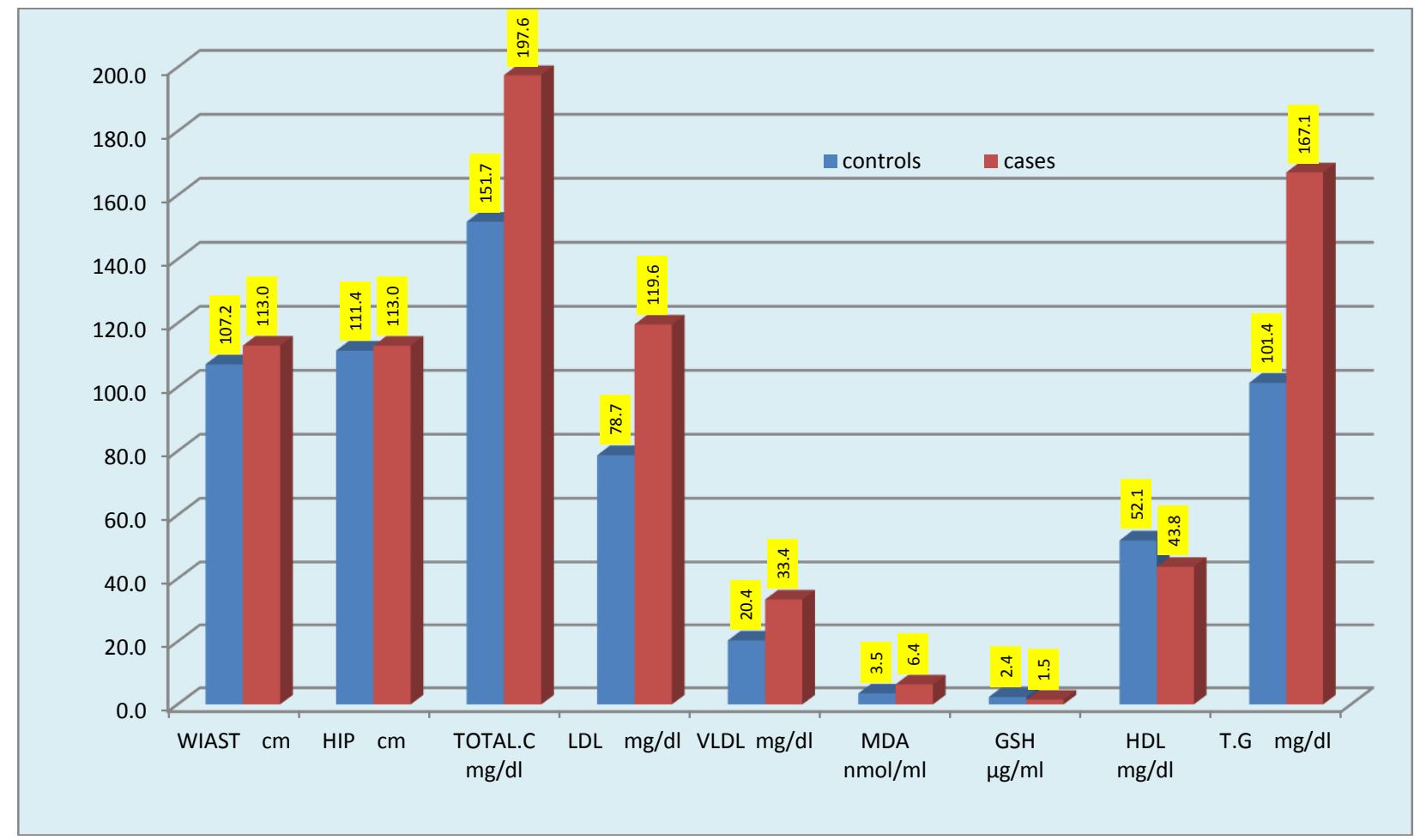

Fig.(1): The waist, Hip and serum Total. C, LDL, VLDL, HDL, TG, MDA, GSH levels in T2DM compared with control samples.

Compared to the control group $(\mathrm{p}<0,0001)$ with $1.03 \pm 0.24$ vs. $1.44 \pm 0.41(\mathrm{mg} / \mathrm{dl})$, $1.49 \pm 0.37$ vs. $2.38 \pm 0.71(\mu \mathrm{g} / \mathrm{ml}), 4.51 \pm 0.70$ vs. $5.37 \pm 0.61(\mathrm{mg} / \mathrm{dl})$, respectively.

This study reveals high prevalence of hypercholesterolemia, hypertriglyceridemia, high LDL-C, VLDL-C. and low level of HDL as compared to non diabetic patients. Similar study among young adult population was done by Sawant et al ${ }^{[18]}$ showed similar results. Insulin affects the liver apolipoprotein production. It regulates the enzymatic activity of lipoprotein lipase (LpL) and Cholesterol ester transport protein. All these factors are likely cause of dyslipidemia in Diabetes mellitus. Moreover, insulin deficiency reduces the activity of hepatic lipase and several steps in the production of biologically active LpL may be altered in DM. The main disorder in lipid metabolism was hypertriglyceridemia in our study. This finding is in concord with our previous study. ${ }^{[19]}$ there is damage to the nephrons.

As a result, kidneys unable to maintain the fluid and electrolytes homeostasis. There is rise in plasma concentration of serum creatinine and urea. In severe hyperglycemia, there is formation of advanced glycation endproducts (AGEs) has long been recognized to cause cellular injury. AGEs accelerates increased vascular permeability, basement membrane thickening and mesangial fibrosis. This process leads to renal failure. ${ }^{[21]}$

In the present study, we noticed a marked increase in HbAlc level in diabetic patients, which could be due to excessive glycosylation of hemoglobin.

Type 2 diabetes mellitus is associated with endothelial dysfunction and oxidative stress. Chronic exposure to elevated glucose and hyper lipidemia can cause damage in different types of cells by variety of mechanisms. Lipids and proteins are the primary target of oxidative stress. ${ }^{[22]}$ Lipid peroxidation of the cellular. 

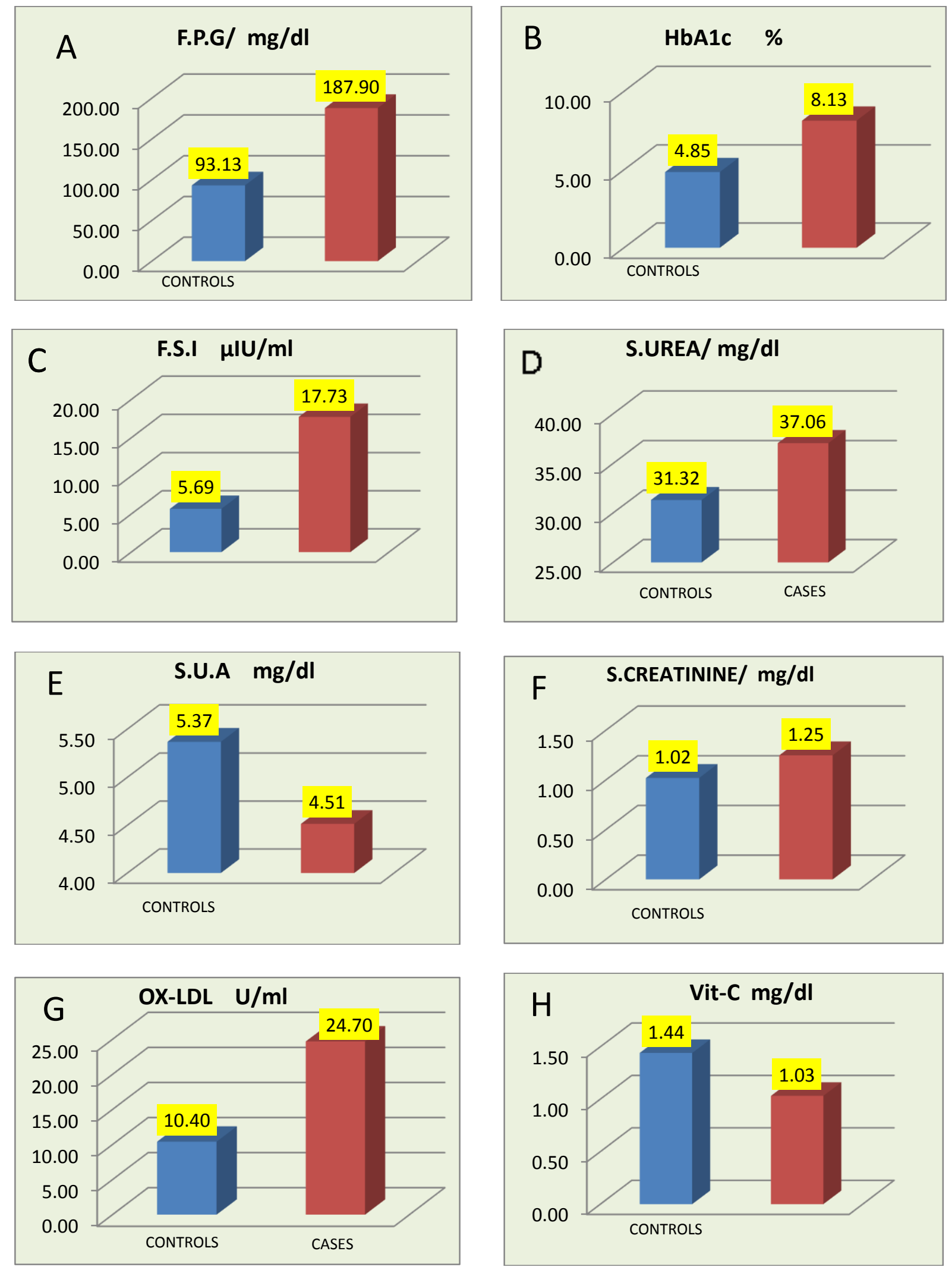

Fig.(2): The Fasting Serum Glucose, HbA1c, FSI, Urea, UA, Creatinine, ox-LDL and Vit-C levels in T2DM males compared with control sample.

Structures, a consequence of increased oxygen free radicals is thought to play an important role in atherosclerosis and micro vascular complications of diabetes mellitus. ${ }^{[23]}$ Our study showed that there are increase in serum MDA, ox-LDL and decrease in serum 
GSH, Vitamin C, UA concentrations in diabetic subjects which is in line with many previous studies. ${ }^{[24]}$ Increased non enzymatic glycosylation and auto oxidation of glucose is the possible mechanism in the excessive production of free radicals in diabetes mellitus which induce lipid peroxidation and increased MDA concentration. MDA is a highly toxic by-product formed in part by oxidation derived from free lipid radicals, and studies have shown considerably raised concentrations in DM. MDA reacts both irreversibly and reversibly with proteins and phospholipids with profound effects. ${ }^{[25]}$ One of the more prominent markers of oxidative stress in DM is oxidized LDL (ox-LDL). Increased production of free oxygen radicals, higher oxLDL levels, along with stimulation of ox-LDL uptake by macrophages and the ensuing promotion of early atherosclerotic changes might be contributed by insulin resistance (IR). hyperglycemia is associated by increased inflammatory burden and increased lipid peroxidation, all leading to enhanced macrophage foam cell formation, low density lipoprotein (LDL) oxidation by macrophages was increased due to the activation of several pro-oxidant systems, as well as the depletion of antioxidants . ${ }^{[26]}$ Moreover, hyperglycemia may lead to intracellular changes in redox state resulting indepletion of cellular $\mathrm{NADPH}+\mathrm{H}$ pool, leading to increased tendency for oxidative stress and high level of oxidized lipoprotein, especially LDL. ${ }^{[27]}$ In addition, the macrophages express scavenger receptors for modified lipoprotein (ox-LDL) permitting them to ingest lipids and become foam cells, the activated macrophage can generate reactive oxygen species that augment oxidant stress. ${ }^{[28]}$

Under in vivo conditions, GSH acts as an antioxidant and its decrease was reported in diabetes. We have observed a significant decrease in GSH content in diabetic erythrocytes. The decrease in GSH content represents increased utilization due to oxidative stress. Glutathione $(\mathrm{GSH})$ is an important cell antioxidant that acts as an electron donor to reduce ROS and acts as a cofactor for NO synthesis from L-arginine.

Depressed GSH levels contribute to decreased NO synthesis. Hyperglycemic states also deplete the NADPH necessary for GSH regeneration, leading to increased oxidative stress. Vitamin $\mathrm{C}$ is a hydrophilic antioxidant in plasma, because it disappears faster than other antioxidants when plasma is exposed to reactive oxygen species. The observed significant decrease in the level of serum vitamin $\mathrm{C}$ could be caused by increased utilization of vitamin $\mathrm{C}$ as an antioxidant defense against reactive oxygen species or by a decrease in GSH, which is required for the recycling of vitamin $C$. Free radicals, the main causes of oxidative stress, may react with variety of biomolecules including lipids, proteins, nucleic acids and macromolecules of connective tissues. Most important physiological antioxidants are vitamin $\mathrm{C}$ and uric acid, while bilirubin and thiol-containing molecules make a comparatively small contribution. Vitamin $\mathrm{C}$ can reduce superoxide, hydroxyl, peroxynitrite radical and other reactive oxidants and may reduce a protective physiological role by preventing lipid peroxidation. ${ }^{[29]}$

\section{Conclusions}

Results of the present study showed that there were increased lipid peroxidation in type 2 diabetic individuals. Free radical formation along with antioxidant deficiency in type 2 diabetes mellitus Iraqi males which play an important role in the development of diabetic complications like diabetic nephropathy, retinopathy, neuropathy, peripheral arterial disease and atherosclerosis.

\section{References}

[1] DeFronz RA, Bonadonna RC, Ferrannini E "Pathogenesis of NIDDM. A balance overview", Diabetes Care, 15(3), 318-368, 1992.

[2] Makris K, Spanou L, Rambaouni-Antoneli $\mathrm{A}$, et al, "Relationship between mean blood glucose and glycated haemoglobin in Type 2 diabetic patients", Diabet Med, 25(2), 174-178, 2008.

[3] Edo AE, Akhuemokhan KL, "Relationships between hemoglobin A1c and spot glucose measurements in Nigerians with type 2 diabetes mellitus", Nigerian Journal of Clinical Practice, 15 (1), 23-29, 2012. 
[4] Cook W, Bryzinski B, Slater J, Frederich $R$, Saxagliptin EA, "efficacy and safety in patients with type 2 diabetes mellitus and cardiovascular disease history or cardiovascular risk factors: results of a pooled analysis of phase 3 clinical trials". Postgrad Med, 125(3), 145-154, 2013.

[5] Nada K, Zorica, C, Đorđe $\mathrm{M}$, et al. "Clinical evaluation of oxidative stress in patients with diabetes mellitus type IIimpact of acute exercise", Vojnosanit Pregl, 66(6), 459-64, 2009;

[6] Nathalie E, Nicolas P, André JS, "Antiinflammatory agents to treat or prevent type 2 diabetes, metabolic syndrome and cardiovascular disease", Expert Opin Investig Drugs, 24(3), 283-307, 2015.

[7] Shankar S, Suchetha KN and Madhu LN "Oxidative Stress, Antioxidant Status and DNA Damage in Type 2 Diabetes Mellitus" RJPBCS, 4 (1), 437-43, 2013.

[8] Shahira RN, Nadia KK, Hoiyda et al. Association of Type 2 Diabetes Mellitus and Glutathione S Transferase (GSTM1 and GSTT1) Genetic Polymorphism. Res. J. Medicine \& Med. Sci, 4(2), 181-88, 2009.

[9] Vandana V, Meena V, Purnim, DS et al. "correlation of vitamin $\mathrm{C}$ with $\mathrm{HbA} 1 \mathrm{C}$ and oxidative stress in diabetes mellitus with or without nephropathy". National Journal of Medical Research, 4(2), 151-55, 2014.

[10] Bashan N, Kovsan J, Kachko I, et al. "Positive and negative regulation of insulin signaling by reactive oxygen and nitrogen species", Physiological Reviews 89(1), 2771, 2009.

[11] Kerstin N, Tobias J, Annika H, et al. "Advanced Glycation End Products and Oxidative Stress in Type 2 Diabetes Mellitus", Biomolecules 5(1), 194-222, 2015.

[12] Giacco F, Brownlee M "Oxidative Stress and Diabetic Complications", Circulation Research, 106:1449-1458, 2010.

[13] Michael, SK, Moses, SE. High density lipoproteins and type 2 diabetes: Emerging concepts in their relationship. World J Exp Med, 2014; 4(1): 1-6.
[14] Grundy SM "Role of low-density lipoproteins in atherogenesis and development of coronary heart disease" Clin Chem, 41(1), 139-146, 1995.

[15] Huggett AST, Nixon DA "Use of glucose oxidase peroxidase and O-dianisine in the determination of blood and urine glucose" Lancet, 273(6991), $368-370$, 1957.

[16] Mustafa K "Simultaneous Determination of Ascorbic Acid and Free Malondialdehyde in Human Serum by HPLC-UV" LCGC ASIA PACIFIC, 7(2), 36-38, 2004.

[17] Lipid Research Clinics Program. Lipid and lipoprotein analysis. In Manual of Laboratory Operations, $2^{\text {nd }}$ ed. Washington DC, U.S. Department of Health and Human Services, p. 63-77. 1982.

[18] Sawant AM, Shetty D, Mankeshwar R et al. "Prevalence of Dyslipidemia in Young Adult Indian Population” JAPI, 56, 99-102, 2008.

[19] Regmi P, Gyawali P, Shrestha R, et al. "Pattern of Dyslipidemia in Type 2 Diabetic Subjects in Eastern Nepal" JNAMLS, 10(1), 11-13, 2009.

[20] Mittal A, Sathian B, Kumar A et al. "Diabetes mellitus as a Potential Risk Factor Disease among Nepalese", Nepal Journal of Epidemiology, 1(1),22-25. 2010.

[21] Vikram BV, Shubhangi AK, Krunal KT, et al. "Thyroid Dysfunction In Patients With Type 2 Djabetes Mellitus At Tertiary Care Center" National Journal of Medical Research, 3(4), 377-380, 2013.

[22] Bogdana V, Maria M, Laura G et al. "Relation Between Inflammation and Oxidative Stress Markers In Diabetic Foot Patients" ROMANIAN J. BIOPHYS, 18(4), 273-282, 2008.

[23] Calabrese V, Cornelius C, Leso AV et al. "Oxidative stress, glutathione status, sirtuin and cellular stress response in type 2 diabetes" Biochimica et Biophysica Acta 1822(5), 729-736, 2012.

[24] Abolghassem J, Mahmoud J, Seyed AK, et al. "Inflammatory biomarkers, antioxidant enzyme activities, and oxidative stress in Iranian male patients with type 2 diabetes mellitus: Effects of eicosapentaenoic acid and vitamin $\mathrm{C}$ 
supplementation" Journal of Research in Medical Sciences, Special Issue (1), s38s41, 2012.

[25] Salem M, Kholoussi S, Kholoussi N et al. "Malondialdehyde and trace element levels in patients with type 2 diabetes mellitus" ARCHIVES oF HELLENIC MEDICINE, 28(1):83-88, 2011.

[26] Nakhjavani M, Esteghamat A, Asgarani $\mathrm{F}$ et al. "Association of oxidized lowdensity lipoprotein and transforming growth factorbeta in type 2 diabetic patients: a cross-sectional study" Transl Res, 153 (2), 86-90, 2009.

[27] Grover-Paez F, Zavalza-Gomez A. "Endothelial dysfunction and cardiovascular risk factors", Diabetes Res. \& Clin Pract. 84(1), 1-10, 2009.

[28] Essam Eldin MN, Abdullah A, Adel MA, et al. "Oxidized low density lipoprotein and total antioxidant capacity in type-2 diabetic and impaired glucose tolerance Saudi men" Diabetology \& Metabolic Syndrome, 6(94), 1-10, 2014.

[29] Hisalkar PJ, Patne AB, Fawade MM. "Assessment of plasma antioxidant levels in type 2 diabetes patients" Int J Med Res, 3(2), 1796-1800, 2012.

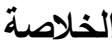

البول السكري واحد من اكثر الامراض انتشارا على

مستوى العالم وهو يرتبط مع عدة اليات واحدة منها الاجهاد التأكسدي الذي يلعب دور مهم في نشوء وتعقيدات المرض.

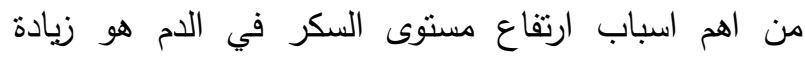

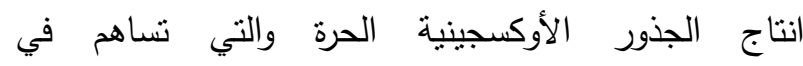

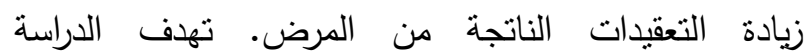
الحالية لتقييم المستويات المصلية لبعض مضادات الاكسدة وكذللك بعض الاصناف (GSH, Vitamin C UA) الأوكسجينية الفعالة (MDA, ox-LDL) لدى الرجال العراقيين المصابين بداء السكري من النوع الثاني ومقارنتها مع الاشخاص الاصحاء. لذلك نم اخذ بـ رجل مصابون بداء السكري من النوع الثاني مع باء رجل نسبة السكر في

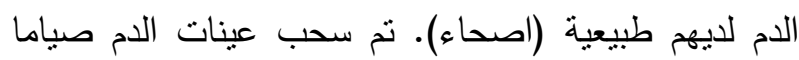

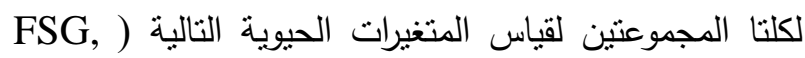
FSI, HbA1c, urea, creatinine, UA, GSH,
Vitamin C, OX-LDL, MDA لتقييم الاختلاف في قيمة المتوسط للفحوصات المختارة بين المجاميع. تم ملاحظة ان المستوى المصلي للمتغيرات التالية FSG, FSI, HbA1c, urea, creatinine, OX-LDL, ) MDA, T.C, TG, LDL,VLDL مهم احصائيا في مرضى السكري مقارنة بالمجموعة

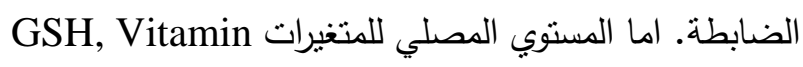
كان منخفضا بشكل مهم احصائيا في (C,UA,HDL) مرضى السكري مقارنة بالمجموعة الضابطة. الامر الذي لني اوضح_الرجال المصابون بداء السكري من النوع الثاني يعانون من حالة اجهاد تأكسدي تبدو واضحة للعيان بشكل

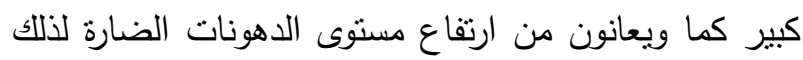

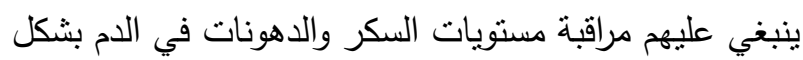
مستمر للحفاظ على حالتهم الصحية بشكل جيد. 